\title{
DETERMINISTIC AND PROBABILISTIC APPROACHES IN THE ANALYSIS OF THE BEARING CAPACITY OF A BRIDGE FOUNDATION ON UNDRAINED CLAY SOIL
}

Jemal J. MUHAMMED ${ }^{1 *}$

\section{Abstract}

This study aims at evaluating deterministic and probabilistic approaches for an analysis of the bearing capacity of a highway bridge foundation on undrained clay soil. The analysis of a rectangular concrete footing was presented for the ultimate strength limit state of the bearing resistance according to the formulation in ES EN 1991:2015 and ERA-Bridge Design Manual, which are the Ethiopian design codes for foundation structures. In the deterministic analysis, the traditional total safety factor method recommended by the ES EN 1991:2015, ERA and AASHTO LRFD method was implemented. It was assumed that design variables such as the soil parameters and loads would follow normal and lognormal distribution functions. With regard to the probabilistic methods, NESSUS-9.8 software, a statistical computer program, was used for the analysis. Comparisons were made between the results obtained from the traditional deterministic method and the reliability-based design approach. The evaluation asserts that the probabilistic approach is a better tool than the deterministic one for assessing the safety and reliability of geotechnical structures. The probabilistic design method rationally accounts for uncertainties more than the conventional deterministic method does. Thus, the author recommends that the National Design Codes of Ethiopia need to be revised and calibrated based on a reliability design format.

\section{Address}

1 Transportation Engineering Program, Civil and Environmental Engineering School, Jimma Technology Institute, Jimma University, Jimma, Ethiopia

* Corresponding author: jj.civil7@gmail.com

\section{Key words}

- Deterministic,

- Probabilistic,

- Reliability,

- Bearing capacity,

- Bridge foundation,

- Undrained clay soil.

\section{INTRODUCTION}

In geotechnical engineering, conventional design methods consider a reasonable global safety factor to account for uncertainties related to loads, materials, the models used, etc. This global safety factor can simply be obtained by dividing the actual strength by the required strength, which indicates whether a system is safe or not; this is termed a deterministic approach. However, due to the high uncertainties resulting from the variability of soils, measurement uncertainties, and transformation uncertainties, such an approach may not represent real conditions. The effect of soil variability cannot be efficiently captured in such a conventional analysis. For such cases, the use of a probability concept can be implemented in terms of a probabilistic or reliability analysis to model uncertainties about the soil (Cederstrom, 2014; Phoon \& Kulhawy, 1999).

Although a deterministic design guarantees a certain degree of structural safety as proposed by the standard prescriptions, it is of interest to consider a probabilistic approach so as to quantify safety and reliability that cannot be assessed with a deterministic method (Russelli, 2008).

Developments in design codes based on reliability-based design (RBD) are actively occurring in various parts of the world today. 
RBD is beginning to be considered as a critical tool in the development of design codes. It is often considered that Eurocode 7 (BS EN 1997-1:2004, 2004), which is recognized as one of the most important geotechnical design codes in the world, introduced this concept (Chew et al., 2015).

These days, geotechnical engineers are involved in the transition from working or allowable stress design (WSD/ASD) to load and resistance factor design (LRFD). LRFD is defined as a method that requires all limit states to be checked using a specific multiple-factor format involving load and resistance factors ( Phoon, 2004).

The objective of this study is to evaluate and compare the deterministic and probabilistic approaches when analysing the bearing capacity of a highway bridge's shallow foundation that was constructed on undrained clay soil.

\section{CONCEPTUAL FRAMEWORKS}

\subsection{Variations of Soil and Loading Parameters}

Among a number of soil properties, the unit weight, cohesion, and friction angle are the most frequently studied variables regarding a reliability analysis of the bearing capacity of shallow foundations. The variation of a parameter is described with the coefficient of variation (COV) of its distribution (Xue \& Nag, 2011). Research done on the COV of soil properties and loads is summarized in Tabs. 1 and 2.

A shallow foundation is designed to resist the loading from structures above it. The variations of loading need to be considered in a reliability analysis of shallow foundations. The variations of loads can be narrow or wide, depending on the nature of the loads.

Tab. 1 The most frequently used coefficients of the variations of soil properties (Xue \& Nag, 2011)

\begin{tabular}{ll}
\hline Soil Property & Range of COV (\%) \\
\hline Unit weight, $\gamma$ & $3-10$ \\
Effective cohesion, $c^{\prime}$ & $10-70$ \\
Effective friction, $\Phi^{\prime}$ : (i) Clay & $10-50$ \\
(ii) Silt & $5-25$ \\
(iii) Sand & $5-15$ \\
\hline
\end{tabular}

\subsection{Reliability and Design Concepts in Geotechnical Engineering}

A critical challenge for an engineer is to define of the safety of an engineering project by including the uncertainty components and doing a reliability analysis on which he can base his decisions. In order to achieve consistent levels of reliability, which are subjected

Tab. 2 COV value for loads

\begin{tabular}{ll}
\hline Load & COV(\%) \\
\hline Dead load & 0.1 \\
Live load (50-year maximum) & 0.25 \\
Snow load (50-year maximum) & 0.26 \\
$\begin{array}{l}\text { Wind load (50-year maximum) } \\
\text { load (50-year maximum, Western }\end{array}$ & 0.37 \\
and Eastern USA) & 1.38 \\
\hline
\end{tabular}

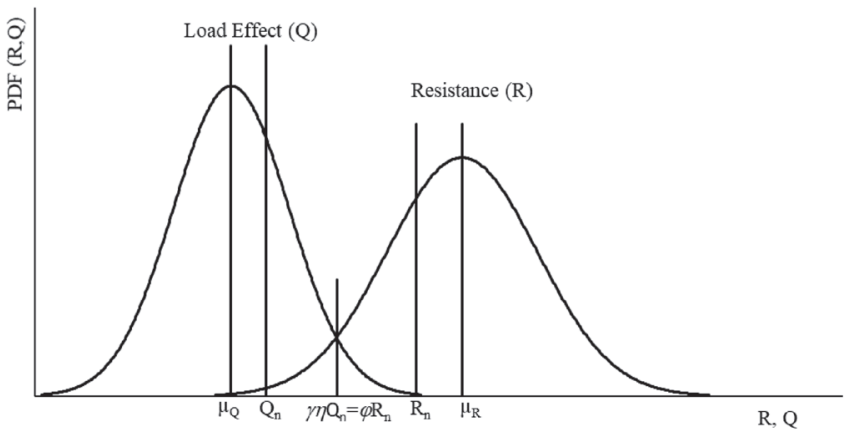

Fig. 1 A simplified reliability-based format: adapted from (NCHRP, 2010)

to substantial economic and social constraints, proper methods are required (Russelli, 2008).

Fig. 1 shows probability density functions (PDFs) for the load effect $(\mathrm{Q})$ and resistance $(\mathrm{R})$. The "load effect" is the load calculated to act on a particular element (e.g., a specific shallow foundation), and the resistance is its bearing load capacity. In geotechnical engineering problems, loads are usually better known than resistances are, so the $\mathrm{Q}$ typically has less variability than the $\mathrm{R}$, i.e, it has a lower coefficient of variation (COV), hence a narrower PDF (NCHRP, 2010).

The design of a shallow foundation has to fulfill two design criteria, namely, the ultimate bearing capacity (i.e., limit state or safety) and tolerable settlements (i.e., serviceability). This study focuses only on the former criterion. A conventional design approach adopts deterministic analyses that usually use representative soil parameters to determine the ultimate bearing capacity. These analyses are based on an assumption of uniformity; the properties of soils are isotropic and homogenous (Chew et al., 2015).

In a deterministic approach, the reliability condition of a bridge foundation has the following form (BS EN 1997-1:2004, 2004; ES EN 1991-1-1: 2015, 2015):

$$
R_{d} \geq Q_{d}
$$

The above relation can also be explained as (NCHRP, 2010; Phoon, 2004; Russelli, 2008; Xue \& Nag, 2011):

$$
S F=R_{d} / Q_{d}
$$

where: $R_{d}$ is a factored bearing resistance/capacity of the foundation, $Q_{d}$ is a factored load applied at the base of the foundation, $S F$ is a safety factor. If $S F<1$, the structure is unsafe; $S F=1-$ at limit state, $S F>1$ stable.

The above relation can be restated in terms of the limit state function, g, which corresponds to the margin of safety, i.e., the subtraction of the load from the resistance, which is a random variable (Naser et al., 2011):

$$
g=R_{d}-Q_{d}
$$

If $g<0$, the designed element or structure is unsafe because the load exceeds the resistance. If $g=0$, it is in a limit state condition, whereas if $g>0$, the structure will be stable with a variable reliability level. This can be described again in terms of the probability of failure and reliability index.

From equation (3) of the performance function, the probability of failure, $p_{p}$ can be computed as (NCHRP, 2010):

So the probability of reliability, $p$, can be obtained as:

$$
\begin{gathered}
p_{f}=P(g<0) \\
p_{r}=1-p_{f}
\end{gathered}
$$


Reliability can be expressed using the "reliability index or safety index" b. For the uncorrelated and normal distribution of variables, $\mathrm{b}$ is the ratio of the mean and the standard deviation of $g$, separating the mean safety margin from the nominal failure value of $g$ being zero:

$$
\beta=\frac{\mu_{g}}{\sigma_{g}}=\frac{\mu_{R_{d}}-\mu_{Q_{d}}}{\sqrt{\left(\sigma_{R_{d}}\right)^{2}+\left(\sigma_{Q_{d}}\right)^{2}}}
$$

where $\mu_{g}$ and $\sigma_{g}$ are the mean and standard deviations of the performance function of the system as stated in Eq. 3, respectively.

If the resistance and load follow normal distributions, then the convolution integral may be evaluated as:

$$
p_{f}=1-\Phi(\beta)=\Phi(\beta)
$$

For nonlinear performance functions, the minimum distance calculation from the Hasofer-Lind principle is an optimization problem, defined by $\beta_{H L}$ minimization, with the constraint condition that the performance function $\mathrm{g}(\mathrm{x})=\mathrm{g}\left(\mathrm{x}^{\prime}\right)=0$. It is possible to consider the correlation between the random variables in the value of the reliability index, which is given as (Pereira \& Caldeira, 2011):

$$
\beta_{H L}=\sqrt{\left(x^{\prime *}\right)^{T} \rho^{-1}\left(x^{\prime *}\right)}
$$

where $x *$ is the point of the performance function closest to the origin in the reduced/transformed coordinates, the named calculation or the design point. $\rho^{-1}$ is the inverse matrix of the correlation coefficients. For this study, a correlation coefficient of 0.4 was used for a correlation established between the random variables of the permanent and variable loads. It is logical to think that as a variable load increases, the permanent load increases as well. As the volume of moving vehicles increases, the concrete depth of a bridge deck would also increase in order to satisfy the span deflection requirements for the additional traffic loads.

The reliability indices for most geotechnical structures and systems lie between 1 and 5, corresponding to probabilities of failure ranging from about 0.16 to $3 \times 10^{-7}$ as shown in Fig. 2. It is possible to compare $\beta$ with the traditional safety factor because both parameters lie in the same range.

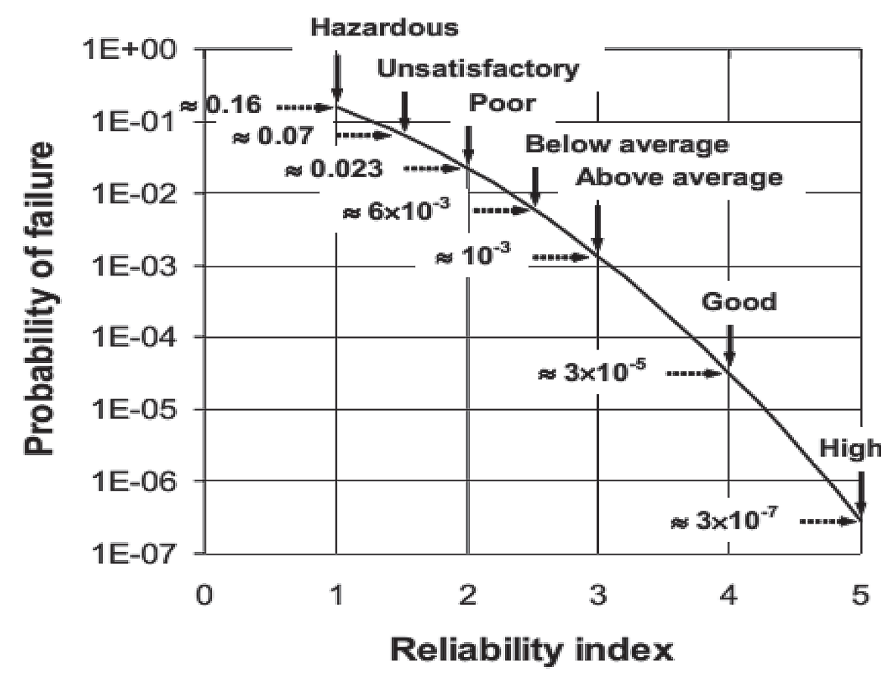

Fig. 2 Relationship between the reliability index and probability of failure (Phoon, 2004)

\section{METHODOLOGY EMPLOYED}

To achieve the stated objectives, an underlying problem was analyzed, i.e., a study of the bearing capacity of a rectangular concrete footing under a masonry abutment on a homogeneous undrained clay soil layer, for which an analytical solution was available. The soil shear strength parameters, i.e., the cohesion and unit weight, are described by specific probabilistic distribution functions, while other soil parameters that are not subject to any significant variation were treated deterministically to reduce the complexity of the problem.

Hence, in this study, an example of a bearing capacity analysis was performed as per ES EN 199: 2015 for the deterministic computation and using NESSUS-9.8 software for the probabilistic analysis. The results from both approaches were then compared using the relationship between the reliability levels and safety margins (ERA, 2002; ES EN 1991-1-1: 2015, 2015).

\subsection{Deterministic Capacity and Loads on a Rectangular Footing}

The factored bearing resistance/capacity of a shallow foundation $\mathrm{R}_{\mathrm{d}}$ can be computed as:

$$
R_{d}=\varphi R_{n}=\varphi \sigma_{u l t}=\varphi\left(5.14 c_{u d S} s_{c} i_{c}+q\right)
$$

Where:

$\varphi$ is a resistance factor; take $\varphi=0.6$ for the clay soil values measured in the lab (ERA, 2002). $R_{n}$ is a nominal bearing resistance or ultimate bearing capacity $\left(\sigma_{u l t}\right)$ of the foundation soil.

$\mathrm{c}_{\text {ud }}$ is the design undrained shear strength; this parameter could influence the bearing strength of the soil and can be obtained from the lab tests. $\mathrm{c}_{\mathrm{ud}}=\mathrm{c}_{\mathrm{uk}} / \gamma_{\mathrm{m}}$, where $\mathrm{c}_{\mathrm{uk}}$ is the characteristic undrained shear strength (usually it is obtained from the laboratory test results), and $\gamma_{\mathrm{m}}$ is the partial safety factor of the soil material; $\gamma_{m}=1.7$ for conventional situations (ES EN 1991-1-1: 2015, 2015).

$\mathrm{s}_{\mathrm{c}}$ is a shape factor, considering that the foundation is rectangular; $\mathrm{s}_{\mathrm{c}}=1+0.2\left(\mathrm{~B}^{\prime} / \mathrm{L}^{\prime}\right)=1.17$; where $\mathrm{B}^{\prime}$ and L' are the effective width and length respectively. To be safer, it was assumed that $\mathrm{B}^{\prime} / \mathrm{L}^{\prime}$ is to be 0.85 .

$i_{c} \quad$ is an inclination factor for the loads applied; as the loads are acting vertically, $i_{c}$ becomes 1 .

$q$ is a surcharge pressure at the base of the foundation, which depends on the depth of the footing from the river bed to the base $\left(D_{f}\right)$, and $\gamma_{s}$ is a unit weight of the backfill soil. $q=\gamma_{s} D_{f}=3 \gamma_{s}$, by assuming $D_{f}=3 \mathrm{~m}$ (considering the scouring effect).

Thus, the above equation can be rewritten as:

$$
R_{d}=0.6\left(5.14\left(c_{u} / 1.7\right) x 1.17 x I+\gamma_{s} D_{f}\right)=2.12 c_{u}+3 D_{f}
$$

For the factored loads applied at the base of the foundation, $Q_{d}$, is calculated as:

$$
Q_{d}=m Q_{n} \text { or } Q_{d}=\sum \eta_{i} \gamma_{i} Q_{i}
$$

Alternatively, consider the factored load as a distributed load:

$$
Q_{d}=\left(\gamma_{k} \eta_{k} G_{k}+\gamma_{Q} \eta_{Q} Q_{k}\right) / A^{\prime}
$$

Where:

$Q_{d}$ is the factored force effect.

$\mathrm{Q}_{i} \quad$ is different, the force affects such permanent characteristic loads (such as the self-weight of a bridge deck, abutment, wing walls, 
footings, and the weight of backfill soils), $G_{k}$; variable characteristic load (such as vehicle loads), $Q_{k}$; and these load effects can be taken as the random variables.

$\gamma_{i}$ is the factor for $\mathrm{i}^{\text {th }}$ loads (dead, live, seismic loads).

$\eta_{\mathrm{i}}$ is the $\mathrm{i}^{\text {th }}$ load modifier; take $\gamma_{k} \eta_{k}=1.3$ and $\gamma_{Q} \eta_{k}=1.6$ (AASHTO, 2012).

$A^{\prime}$ is an effective area and is equal to $\mathrm{B}$ 'xL for a rectangular footing, which is eccentric in the direction of $\mathrm{B}$, where $\mathrm{e}_{\mathrm{B}}$ is different from zero, while it is centric in the direction of $\mathrm{L}$, where $\mathrm{e}_{\mathrm{L}}$ is zero.

Hence, the above equation can be recomputed as:

$$
\begin{aligned}
Q_{d} & =1.3 G k /\left(\left(B-2 e_{B}\right) * L\right)+1.6 Q k /\left(\left(B-2 e_{B}\right) * L\right) \\
& =1.3 G k /((B-1) * L)+1.6 Q k /((B-1) * L)
\end{aligned}
$$

For the sake of a simplified analysis, by limiting the eccentricity in the direction of $\mathrm{B}$, it has been assumed that $2 e_{B}=1 \mathrm{~m}$. For a $10 \mathrm{~m}$ wide bridge deck, $\mathrm{L}$ was taken as $12 \mathrm{~m}$. The foundation under the abutment was considered in this study. Therefore, for the structure to be safe, equation (1) should be satisfied.

Gk and Qk were estimated using Design Approach 3 (DA3) as stipulated in ES EN 1991:2015 (BS EN 1997-1:2004, 2004; ES EN 19911-1: 2015, 2015). The dead (permanent) loads were computed from the bridge superstructure (slab deck, girder, beam seat, back wall), bridge masonry abutment, wing wall, and backfill materials, whereas the live (variable) loads were estimated from vehicle traffic loads.

\subsection{Probabilistic Bearing Capacity}

In the present work, the probabilistic analysis for the bearing capacity of a rectangular footing was conducted with the NESSUS-9.8 statistical computer program by utilizing the First-Order Reliability Model (FORM) analysis method, i.e., by considering the uncertainty of the parameters associated with the input variables and the correlations among the random variables.

Among all the variables of equations (10) to (13) input, $c_{u}, \gamma_{s}, G_{k}$ and $Q_{k}$ could contribute significantly to the uncertainty of the parameters input and be assumed to be random variables. Besides, the footing width $(B)$ and depth of the foundation $\left(D_{f}\right)$ are likely to provide uncertainty about marginal parameters (Naser et al., 2011) and thus were assumed to be deterministic for this study. It should be noted that uncertainty about the model was not considered in the present work and that those equations (1)-(3) were assumed to be perfect predictors (i.e., there is no model uncertainty).

To evaluate the reliability and stability of the foundation structure, the calculated $p_{f}$ should be less than the target probability of failure $p_{o}$. The $p_{o}$ values are recommended to be within an average range of $1 \times 10^{-4}$ to $1.35 \times 10^{-3}$ as per the recommendations of several authors. Similarly, considering the soil's variability, the reliability indices suggested in different literature lie in an approximate range of 3 to 4 (AASHTO, 2012; Cederstrom, 2014; NCHRP, 2010; Phoon, 2004). For this particular study of a rectangular bridge foundation, when considering the load modifier (AASHTO, 2012), a target reliability value of 3.5, and a corresponding probability of an exceedance of $\mathbf{7 . 5}$ $\mathbf{x} 10^{-4}$ during the 75 -year design life of the bridge was proposed.

\subsection{Steps of the Analysis in the NESSUS-9.8 Computer Program}

The following steps were systematically followed during the analysis using NESSUS-9.8.

1) Defining the problem statement: write the 'Performance Function' equation using Eqs. (3), (10), and (13).

2) Input the random variables $\left(c_{u}, g_{s}, G_{k}\right.$, and $\left.Q_{k}\right)$ as given in Tab. 3.

3) The probabilistic analysis, such as 'specified performance level', and 'full cumulative distribution' options, were used alternatively. The analysis was done using FORM and other methods for the following sub-cases:

a) Varying the width of the rectangular footing B, while the other random variables were kept the same until a safe and optimum width was achieved.

b) Varying the characteristic mean value of the undrained shear strength, cu for constant $\mathrm{COV}$, while the other random variables were kept constant.

c) Varying the COV of cu for a constant mean value, while the other random variables were kept the same.

d) Varying the characteristic mean value of the variable load, $\mathrm{Q}_{\mathrm{k}}$, for a constant coefficient of variation $(\mathrm{COV})$, while the other random variables were kept the same.

\section{ANALYSES AND DISCUSSION OF THE RESULTS}

This section presents and discusses the results which were obtained from the NESSUS computer program analysis, a comparison between the traditional general safety factor approach, the response function, and a reliability-based probabilistic analysis, as well as an analysis of the probabilistic sensitivity factors to identify the most dominant random variables. A summary of the primary outputs for the benchmark random variables input is presented in Tab. 4 .

Tab. 4 presents the probability of failure, the reliability index, sensitivity factors, and deterministic value (performance function) for the random variables input by varying the width of footing (B) based on the FORM method. The width of the footing significantly increases the safety performance of the footing system. For the first trial, $B=6 \mathrm{~m}$ width, as per the threshold values considered in this study, the estimated value of the probability of failure $\left(P_{f}\right)$ is higher than the limit value $\left(7.5 \times 10^{-4}\right)$, while the reliability index $(\beta)$ is less than the target value (3.5). Furthermore, the deterministic response function $g$ value for the same width was found to be less than 0 . This proves that the foundation is unsafe to support the loads applied and that the foundation would fail in shear.

Tab. 3 The Random Variable Inputs Utilized in the NESSUS - Benchmark input values

\begin{tabular}{llllll}
\hline Ser. No. & Random Variables & Mean, $\boldsymbol{\mu}$ & COV \% & Distribution & Reference \\
\hline 1 & Undrained shear strength, $\mathrm{c}_{\mathrm{u}}\left(\mathrm{kN} / \mathrm{m}^{2}\right)$ & 50 & $20 \%$ & Lognormal & Phoon $(2004)$ \\
2 & Unit weight of backfill, $\gamma_{\mathrm{s}}\left(\mathrm{kN} / \mathrm{m}^{3}\right)$ & 19 & $5 \%$ & Normal & Chew et al. (2015) \\
3 & Permanent characteristic load, $\mathrm{G}_{\mathrm{k}}(\mathrm{kN})$ & 7000 & $10 \%$ & Normal & Pereira et al. (2011) \\
4 & Variable characteristic load, $\mathrm{Q}_{\mathrm{k}}(\mathrm{kN})$ & 600 & $20 \%$ & Lognormal & Pereira et al. (2011) \\
\hline
\end{tabular}


Tab. 4 Probability of failure, reliability index, and sensitivity factors and deterministic value of $g$ for different footing widths, B (using FORM method for 'specified performance level, $g=0.00$ ').

\begin{tabular}{|c|c|c|c|c|c|c|c|c|c|}
\hline \multirow[t]{2}{*}{ Ser. } & \multirow[t]{2}{*}{ Value of B (m) } & \multirow[t]{2}{*}{$\begin{array}{l}\text { Estimated proba- } \\
\text { bility of failure, } p f\end{array}$} & \multirow[t]{2}{*}{$\begin{array}{l}\text { Calculated reli- } \\
\text { ability index, } \beta\end{array}$} & \multirow[t]{2}{*}{$\begin{array}{l}\text { Deterministic } \\
\text { response, } g\end{array}$} & \multirow[t]{2}{*}{$\begin{array}{l}\text { Total Safety } \\
\text { factor } S F\end{array}$} & \multicolumn{4}{|c|}{$\begin{array}{l}\text { Probabilistic Sensitivity levels, for } \\
(\partial \mathbf{p} / \partial \mu)(\sigma / p) \text { index }\end{array}$} \\
\hline & & & & & & $c_{u}$ & $\gamma_{s}$ & $G_{k}$ & $Q_{k}$ \\
\hline 1 & 6 & $6.77 \mathrm{E}-01$ & 0.97 & -16.80 & 0.97 & -1.14 & -0.18 & 0.93 & 0.20 \\
\hline 2 & 8 & 7.72E-02 & 1.50 & 31.53 & 1.39 & -1.96 & -0.31 & 1.17 & 0.25 \\
\hline 3 & 10 & 5.77E-04 & 3.55 & 61.60 & 1.79 & -4.45 & -0.76 & 2.24 & 0.48 \\
\hline 4 & 11 & $2.95 \mathrm{E}-05$ & 4.50 & 72.17 & 1.99 & -5.79 & -1.04 & 2.76 & 0.58 \\
\hline 5 & 12 & $8.69 \mathrm{E}-07$ & 5.37 & 80.74 & 2.52 & -7.19 & -1.33 & 3.22 & 0.68 \\
\hline 6 & 14 & $2.85 \mathrm{E}-10$ & 6.54 & 93.99 & 2.75 & -9.95 & -2.01 & 4.11 & 0.84 \\
\hline 7 & 16 & $3.62 \mathrm{E}-14$ & 7.01 & 103.70 & 3.17 & -12.60 & -2.75 & 4.88 & 0.95 \\
\hline
\end{tabular}

At $B=10 \mathrm{~m}, \quad P$ becomes $5.77 \times 10^{-4}<\mathbf{7 . 5} \times \mathbf{1 0}^{-4}$ and $\beta$ is $3.55>$ 3.5. This condition satisfied the requirements as per the reliability-based design approach, and the foundation can support the loads. By increasing the B value beyond a $10 \mathrm{~m}$ width, the foundation would become safer in a reliability-based analysis format.

For the safety margin method, when considering the widths of $6 \mathrm{~m}$, the performance function $(\mathrm{g})$ is less than 0 , and the total safety factor (SF) is less than 1. This confirms that the width of the footing is insufficient and that the underlying soil is unable to resist the pressure applied. At B $=8 \mathrm{~m}, \mathrm{~g}>0$ and $\mathrm{SF}>1$, the foundation is theoretically stable. The performance function has a limitation in telling us when to stop our calculations of the footing dimensions once they meet the safety requirements. However, the SF method overcomes this limitation so that $\mathrm{SF} \geq 2.5$ satisfies our design requirements for a bridge foundation (AASHTO, 2012; ES EN 1991-1-1: 2015, 2015). The required total safety factor was achieved at $\mathrm{B}=12 \mathrm{~m}$, i.e., the value at which the system achieves its safety requirements. However, the total safety factor method satisfied the requirement at a greater width than the probabilistic approach did. Thus, it can be inferred that the reliability-based design better describes the safety and reliability and is also economical as compared to the deterministic method for an analysis of the bearing capacity of a bridge foundation on undrained clay soil.

The probabilistic sensitivity factors are presented in Tab. 4 and Figs. 3 and 4. Fig. 3 shows that the undrained shear strength $\left(c_{u}\right)$ was the most sensitive parameter among all the random variables involved in the probabilistic analysis. It significantly influenced the probability of failure $\left(\mathrm{p}_{\mathrm{f}}\right)$ and the performance function with respect to its mean value. From the index $(\partial \mathrm{p} / \partial \mathrm{m})(\sigma / \mathrm{p})$ values, increasing both the mean value of the undrained shear strength $\left(\mu_{\mathrm{cu}}\right)$ and the unit weight $\left(m_{g s}\right)$ contributed to the reduction of $\mathrm{p}_{\mathrm{f}}$ as demonstrated in Fig. 4. Moreover, $\mathrm{m}_{\mathrm{cu}}$ influenced the $\mathrm{p}_{\mathrm{f}}$ value more than $\mu_{g s}$ did. This shows that parameter $\mathrm{c}_{\mathrm{u}}$ has a higher relative importance than the other random variables on the performance output of the response function. Hence, it suggests that it is essential to control (limit) the uncertainty associated with this random variable to obtain a greater improvement on the probabilistic performance, whereas the permanent load $Q_{k}$ has a positive contribution to the probability of failure with respect to its mean value. On the other hand, the sensitivity level for the index $(\partial \mathrm{p} / \partial \mathrm{s})(\sigma / \mathrm{p})$ with respect to the standard deviation is zero. This might be due to a correlational relationship found among the random variables involved in the probabilistic sensitivity analysis.

\section{RELIABILITY-BASED PARAMETRIC STUDY}

\subsection{Effect of Undrained Shear Strength on the Reliability Index}

As per the discussion in the previous section, $\mathrm{c}_{\mathrm{u}}$ is the most sensitive input parameter that could affect the performance function and stability of a bridge foundation. Hence, it is imperative to evaluate and compare its effect on the reliability level of the foundation system. The $c_{u}$ value of the clay soil considered ranges from 25-150 $\mathrm{kN} / \mathrm{m}^{2}$, which was obtained from an unconfined compressive test (Phoon, 2004).

As Fig. 5 depicts, as the undrained shear strength of the clay soil increased, the reliability index of the bridge foundation increased

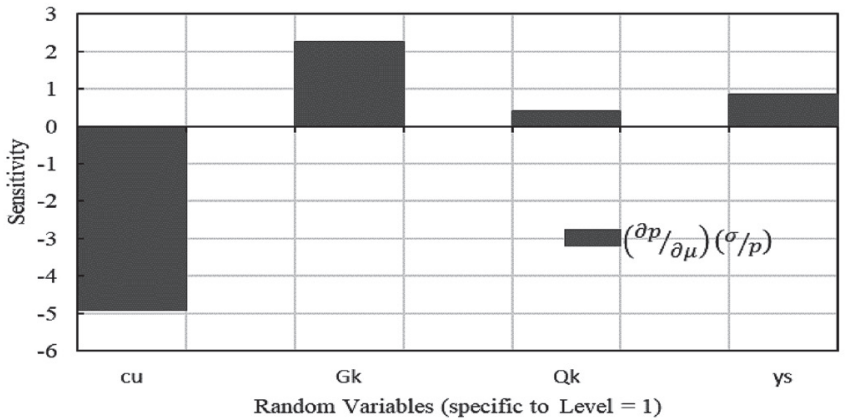

Fig. 3 Sensitivity levels of the random variables for $B=10 \mathrm{~m}$

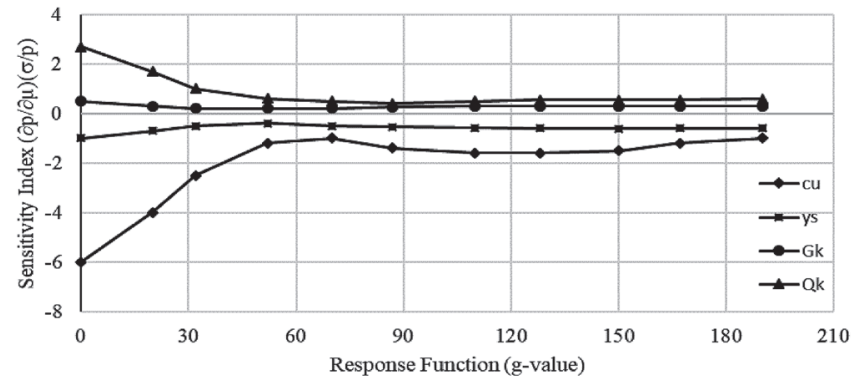

Fig. 4 Probabilistic sensitivity factors for $B=10 \mathrm{~m}$ from the 'full cumulative distribution' of FORM 


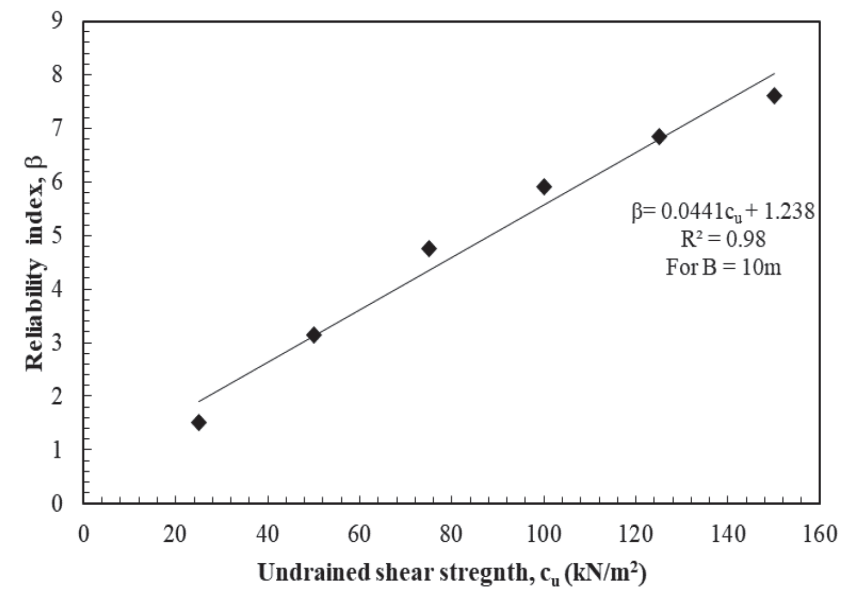

Fig. 5 Undrained shear strength and reliability index curve

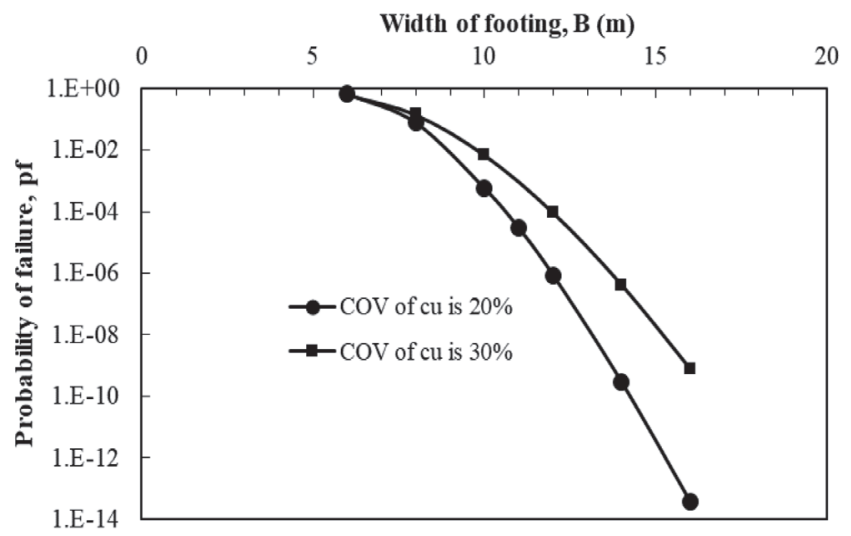

Fig. 7 Width of footing and probability of failure for different $\mathrm{COVS}$ of $c_{u}$

proportionally. The relationship between the reliability index and undrained shear strength can be represented by a linear correlation formula as shown in Fig. 5. The correlation between the two variables is very strong and has a high coefficient of determination as the line equation indicates.

\subsection{Effect of the Width of the Footing on the Reliability Index and Probability of Failure}

Table 4 shows that the reliability index of the bridge foundation is highly dependent on the width of the footing. Thus, the curve of the width of footing B versus the reliability index is presented in Fig. 6. One can see from the figure that as the width of the foundation increased, the reliability index also correspondingly increased, and the other random variables input were kept constant. Meanwhile, it can be observed that as the coefficient of variation increased, the reliability index decreased for a given footing width. However, as the COV value of undrained shear strength increased, the reliability index would decrease for the same footing width. This means that the higher COV value indicates the high degree of uncertainty of the random variable $(c)$; subsequently, the stability of the foundation began decreasing.

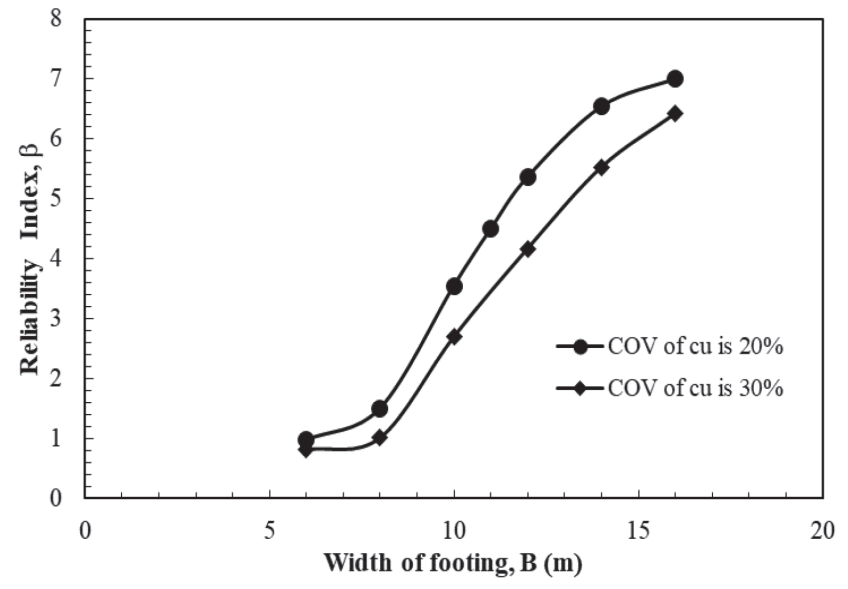

Fig. 6 Width of footing and reliability index curve for different $\mathrm{COV}$ of $\mathrm{cu}$

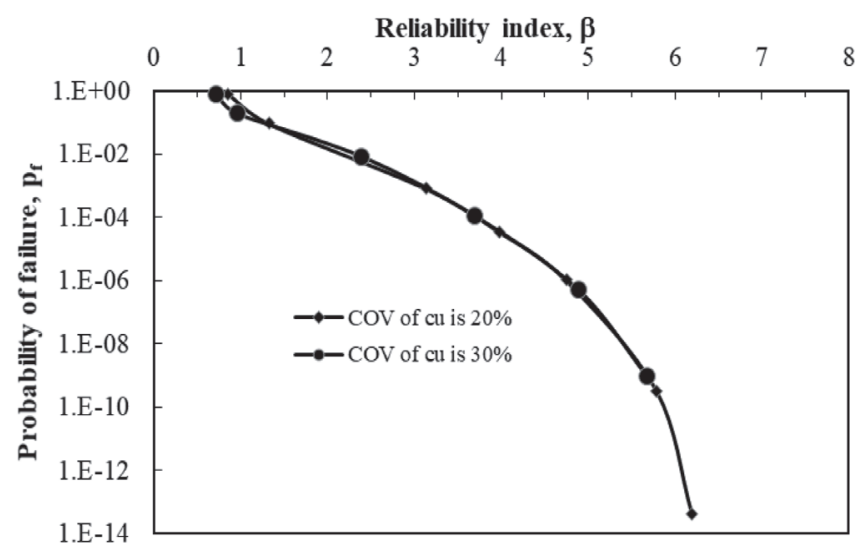

Fig. 8 Reliability index and probability of failure for different COVS of $c_{u}$

Fig. 7 shows that as the width of the footing increased, the probability of failure began decreasing. This indicates that a bridge foundation becomes stable as width B gets larger and larger. Besides, as the COV of the undrained shear strength increased, the probability of failure would increase for the same footing width. The uncertainty of the input parameters highly contributed to the probability of the failure of the structures. Therefore, the coefficient of variation (COV) of the random variables significantly affects the stability and reliability of a bridge foundation on undrained soil conditions in this particular study.

Fig. 8 presents the relation between the probability of failure and the reliability index for different COV values of undrained shear strength. It is evident that the reliability (safety) index increased as the probability of failure increased. However, the variation of COV value did not affect the relationship between the reliability index and the probability of failure curves directly.

\subsection{Reliability Index, Safety Factor and Coefficient of Variation}

Fig. 9 demonstrates the relationship between the reliability index and the safety factor of the foundation structure. An increment in the safety factor would contribute to an improvement of the reliability index. The graph shows the relationship of the safety factor and reliabil- 


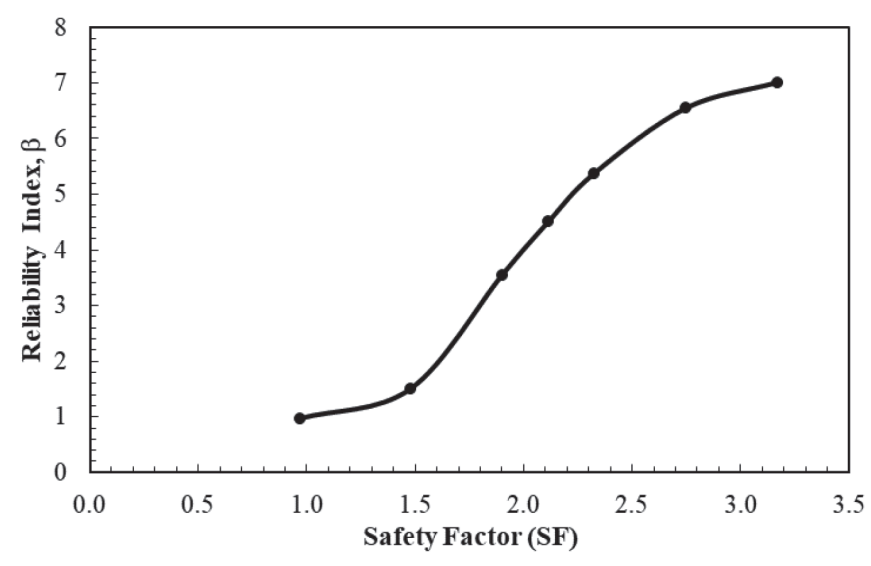

Fig. 9 Reliability index vs. Safety factor

ity index to be near the unity value; beyond a safety factor of three, it is very gentle, unlike the segment in between these two values, which is quite steep. In this steep segment, the correlation between the safety factor and reliability index is very significant and sensitive.

The results of the reliability index significantly depend on the value of the coefficient of variation. The reliability index of the footing structure decreased as the coefficient of the variation of the undrained shear strength increased as presented in Fig. 10.

\section{CONCLUSIONS}

This study has attempted to compare an analysis of the bearing capacity of a foundation of a masonry abutment of a bridge structure on undrained clay soil. The analysis was based on the traditional deterministic design approach, which refers to the Ethiopian geotechnical structure design standards and a reliability-based design using NESSUS 9.8, a statistical computer program. The comparison was well demonstrated using a typical example of a concrete footing having dimensions of $12 \times 12 \mathrm{~m}$. From an analysis of the results,

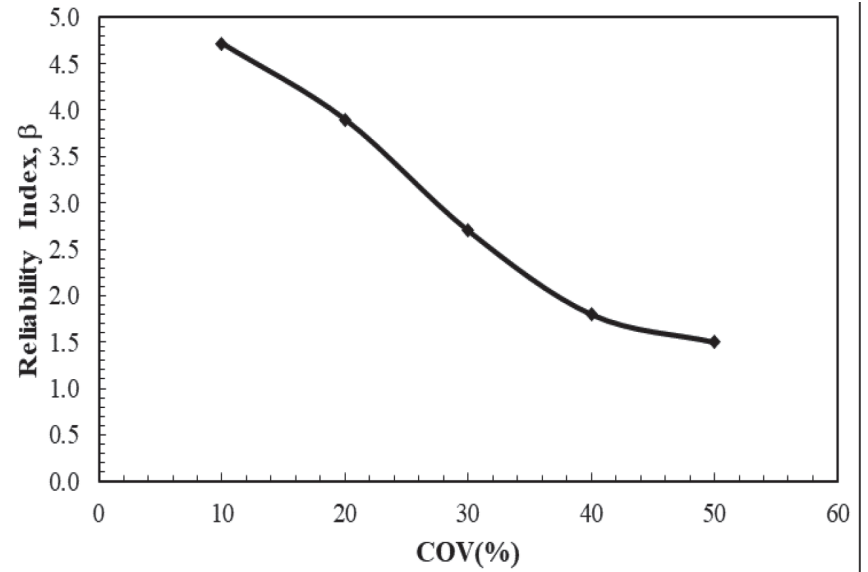

Fig. 10 Reliability index vs. COV of $c_{u}$

one can understand that the reliability-based design provides a more consistent means of managing and describing uncertainties in many ways than its predecessor, the deterministic approach, does. The results of the analysis also show that the level of safety determined by the probabilistic method was achieved with a smaller width of footing in comparison with the traditional total safety factor method from ES EN 1991:2015 and the ERA-Bridge Design Manual. The conventional safety factor method is more conservative than the probabilistic analysis method in determining the stability and safety requirements. Thus, it is recommended that the national design codes of Ethiopia be revisited and that the codes should include the probabilistic method of design approach. The safety and reliability of the structures can be described in a better way in terms of the probability of failure and the target reliability index as per the demands of clients.

As a future development of this work, beside calibrating the traditional deterministic approach to a reliability-based approach by considering uncertainties from the properties of soils and loads, it is also imperative to include other sources of uncertainties that are specific to the local conditions such as spatial variabilities, construction activities, and precision of the calculation models. 


\section{REFERENCES}

AASHTO (2012) LRFD Bridge Design Specifications, American Association of State Highway and Transportation Officials, Washington, DC, USA.

BS EN 1997-1:2004 (2004) Geotechnical design Part 1: General rules. Eurocode 7. British Standards Institute. https://doi. org/10.1680/igeng.1997.28998

Cederstrom, E. (2014) Application of Probabilistic Methods in Slope Stability Calculations, Chalmers University of Technology, Gothenburg, Sweden 2014:91.

Chew, Y. M. - Ng, K. S. - Ng, S. F. (2015) The effect of soil variability on the ultimate bearing capacity of shallow foundation. Journal of Engineering Science and Technology, 10 (Spec. Issue on Advances in Civil and Environmental Engineering ACEE 2015), $1-13$.

ERA. (2002) Bridge Design Manual, Ethiopian Roads Authority, Addis Abeba, Ethiopia.

ES EN 1991-1-1: 2015. (2015) Geotechnical Design : General Rules, Ministry of Construction, Addis Abeba, Ethiopia.

Naser, A.-H. - Kramer, W. M. - Anderson, S. - Nichols, S. (2011) Implementation of LRFD Geotechnical Design for Bridge Foundations, Design Guidance for Bridge Foundations. https://doi. org/Report No. FHWA NHI-10-039, (2011).
NCHRP. (2010) LRFD Design and Construction of Shallow Foundations for Highway Bridge Structures, Washington, D.C. https:// doi.org/10.17226/14381

Pereira, C. - Caldeira, L. (2011) Shallow Foundation Design through Probabilistic and Deterministic Methods, In: Bundesanstalt für Wasserbau ISBN- ISGSR 2011 (pp. 199-207).

Phoon, K. K. (2004) Towards reliability-based design for geotechnical engineering Singapore.

Phoon, K. - Kulhawy, F. H. (1999) Evaluation of geotechnical property variability, Canadian Geotechnical Journal, 36, 625-639.

Russelli, C. (2008) Probabilistic Methods Applied to the Bearing Capacity Problem, Universität Stuttgart. https://doi.org/10.1017/ CBO9781107415324.004

Xue, J. - Nag, D. (2011) Reliability analysis of shallow foundations subjected to varied inclined loads, In: Bundesanstalt für Wasserbau ISBN-ISGSR2011 (pp. 377-384). 